\title{
Governance for Sustainability in an Organization in Central Mexico
} \author{
Rubén Sandoval-Vázquez ${ }^{4}$, Jorge Hernández-Valdés ${ }^{5}$ \\ ${ }^{1}$ National Autonomous University of Mexico, Iztapalapa, Mexico City \\ ${ }^{2}$ Metropolitan Autonomous University, Azcapotzalco, Mexico City \\ 3,5National Autonomous University of Mexico, Coyoacan, Mexico City \\ ${ }^{4}$ Autonomous University of State of Morelos Cuernava, Morelos.
}

José Marcos Bustos-Aguayo ${ }^{1}$, Margarita Juárez-Nájera ${ }^{2}$, Javier Carreón-Guillén ${ }^{3}$, Francisco

\begin{abstract}
Often, the total quality has been instrumented before being weighted. The strategies even precede a diagnosis in Mexican organizations, but in an opposite sense, the present work set out to establish the reliability and validity of an instrument to measure the perception of total quality based on three indicators related to management. , production and transfer of knowledge. A nonperimental study was carried out with a non-probabilistic selection of 124 administrative staff and employees from an organization in central Mexico. From a structural model $\left\{X^{2}=123,24\right.$ (23df) $p=0,010 ; G F I=0,990 ; C F I=, 991 ; I F I=0,993$; RMSEA $=0,007 \mathrm{~J}$, it was found that management affects production $(0,38)$ and this about the total perceived quality $(0,35)$, although there are lines of research concerning empathy, commitment, entrepreneurship, satisfaction and happiness in relation to the implementation of continuous improvements to the quality of processes and products.
\end{abstract}

Keywords-Client omission, Control strategy, Logistics mistake, Wrong delivery.

\section{INTRODUCTION}

No doubt, organizations have some mistakes in its organizational context, however, sometimes, mistakes are over-dimensioned because of clients' honest lack. It is when the organization need to have a severe control of it processes, even administrative, financial, sales, production or logistics ones. Organizations which promote the use, production or consumption of green energies, also are attached to negative factors occurrence over its processes. Present document, look forward to be a path on mistake occurrence, when it is considered the logistics' or deliveries' mistakes, in the framework of sustainability's context, due to the need of green organizations hold in the market to promote clean energy methods.

Concern about sustainability has been grown in people's mind. Debate since the release of the World Conservation
Strategy in 1980, "Our Common Future" the report of the World Commission On Environment and Development in 1987 and Agenda 21 in 1992 has resulted in gradual acceptance that sustainability must integrate ecological integrity, economic efficiency and social equity (Côté\& Cohen-Ronethal, 1998).

In Molina Ruiz (2013), it is mentioned that there exists an alarming situation, due to planets situation. In Mexico, it is possible to see the negative influence of population impact over environment (Molina-Ruiz, 2015). It is also possible to observe some social deterioration and economic problems. Cavagnaro\& George (2017) propose a framework in which they are recognized the three main dimension of sustainability.

It is important to promote wellbeing inside the organizations. In the framework of sustainability, organizations which promote use of clean energies, sometimes are in a constant risk that threaten its stability.

It is natural for organizations to have some mistakes along its development and historical path, however, when client shows a lack of honesty and omit information sharing, the organization have a higher spend of resources to correct the mistake or repair the problem. Between organizations it is necessary to create a supporting environment in which the stakeholders share information with each other.

In order to survive on the market and achieve profitability, the companies need to meet customer requirements and perform their activities in an efficient way (Andrejić, Kilibarda \& Popović, 2015). However, some clients abuse of the organizations good will, bringing extra cost in the organizational use of resources.

Sometimes, inside of the organizations, low compromised personnel have cheating attitudes that affect directly the organization performance. In Bohte\& Meier (2000), it is defined organizational cheating as an attempt to manipulate performance criteria; it is also identified three major forms of 
organizational cheating:1) cutting corners (doing sloppy work); 2) lying (making up organizational results); and 3) biasing samples (reporting most conductive cases).In the organizational context it can be identified another way of organizational cheating, "client's snuggling”, which means that a stakeholder inside of the organization overprotect the client, giving to it privileged information and covering bad client (or supplier) behavior that affects the organization.

Cialdini, Petrova\& Goldstein (2004), proposed that organizational dishonesty can increased surveillance, (mis)matches between values of employee and organization and/or reputation degradation. It is also possible to state that organization dishonesty can make that enterprise run out of business (bankruptcy), loss of clients, loss of suppliers, loss of bank or credit-agents' support.

Enterprise in which it happened the case under study had certain particularities. It is an enterprise relatively new in the photovoltaics sector in Mexico, it was created in 2013. Due to its recent creation, there was a lack in the control and organization of different activities inside of the organization. That organization has the second place in sales in Mexican market, during 2015. During 2017, it has increased its market share to North America and Central America. In Mexico, the enterprise recovers the second position in importance by Mexican PV-market.

First detected particularity was, as here exist a cordial and close communication, delivery of final product would be required via a piece of paper written by sales manager and given to production manager.

Despite there exist four main steps to deliver a merchandize, sales manager, due to urgency of delivery, avoid the sequence of steps. The correct step by step in the enterprise would be as follows: (a) quotation price document, in which sale's agent sent the price and characteristics of the product to client, in case client accept the price and characteristics, it is generated (b) the request document, in which warehouse is notified that a product need to be packaged, it also is sent to the client so he/she can make the payment, to make (c) the invoice document, which is the official document and ensures that merchandize is now client's property, once invoice is created, it is made a (d) warehouse authorization, a list of the allowed merchandise's delivery to client, via Delivery-service outsourcing.

Sometimes it was authorized the delivery of merchandize, when the quotation price document was just generated, because of the request of sales manager.

There were some situations in which sales manager sent a "request document" to logistics department (warehouse), with missed information, and after, she resent mentioned document with extra information or with corrections in the information, or sales manager hold the (extra) information document (or the corrected one) for itself.

Warehouse do not have a complete folder for each delivery. Deliveries were just registered in a list with very little information, and the folder for each delivery (invoice) do not have all of the documents.

\section{Theory of perceived quality}

In the anthropocentric paradigm in which companies circumscribed their total quality control to the demands of the market and the specific demand of their clients, the function of the leader was that of an intermediary who managed and managed the risks without considering the environment or capital nor the possibilities of human or intellectual capital in face of the imbalance that the situation implied (see Figure 1).

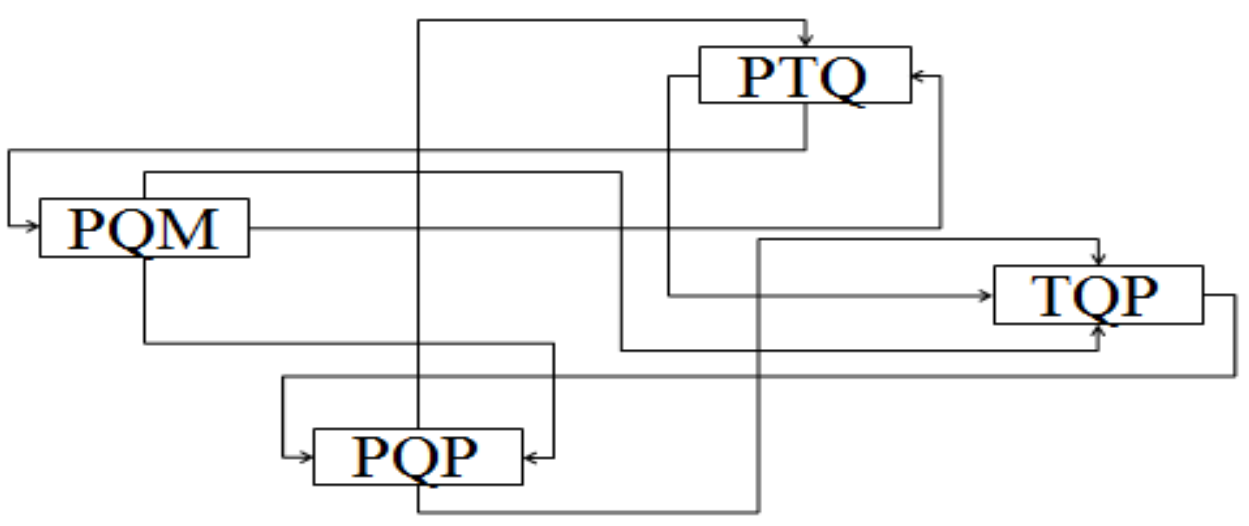

$\mathrm{TQP}=$ Total Quality Perceived, $\mathrm{PQM}=$ Perceived quality management, $\mathrm{PQP}=$ Perception of quality production, $\mathrm{PTQ}=$ Perceived Transfer of Quality

Fig.1: Theory of Perceived Quality

Source: Prepared by the author 
In the paradigm of sustainability, the total quality lies in the evaluation, certification and accreditation of processes based on the availability of resources, policies against climate change, the effects on environmental public health and the risks inherent in the Industrial production (Acar\&Acar, 2014).

While in the old anthropocentric paradigm the responsibility was centered on the leader, the manager or administrator, in the new ecocentric paradigm the responsibility is shared (Hernandez \& Valencia, 2016). This implies a unilateral communication versus a bilateral communication, a unidirectional motivation versus a bidirectional motivation. It is about the confrontation of two cultures, one authoritarian and the other democratic (Anicijevic, 2013).

Even the new environmental paradigm is distinguished from the previous dominant paradigm by the continuous improvement of processes (Mendoza, Ramirez \&Atriano, 2016). This supposes the entrepreneurship and the innovation of the processes that in the previous paradigm was translated in a resistance to the change. That is to say that the responsibility of participation and initiative now concerns all those who integrate the organization (Carreón et al., 2014).

The achievement of a shared responsibility precedes a shared work commitment and a climate of emotional, affective and sentimental relationships regulated and oriented to coexistence, respect, solidarity and support among those who make up the organization (Cruz, Arroyo \&Marmolejo, 2016).
Therefore, there to define quality standards and criteria for its continuous improvement, the organization involves leaders and managers, managers and employees in the objectives, tasks and goals according to the availability of resources, social responsibility and organizational capabilities (Escobar, 2014).

\section{Specification model}

\section{Formulation}

Will the relationships proposed in the theory of perceived quality be adjusted to empirical observations with leaders and employees of an organization in central Mexico?

\section{Null hypothesis}

The relationships between the variables specified in the theory of perceived quality will be adjusted to the data observed in an organization in central Mexico, since it is a universal asymmetric relationship between the demands of the environment and organizational capacities, which also mark differences between leaders and employees

\section{Alternative hypothesis}

Although the theory of perceived quality anticipates scenarios of differentiation between the requirements of the environment and the capabilities of the organization, among leaders and employees, the perceptions around the total quality process, as well as control management are different in each organization reason why the relationships established in the theory will not conform to the observations of a case study

\section{Relations on the factors}

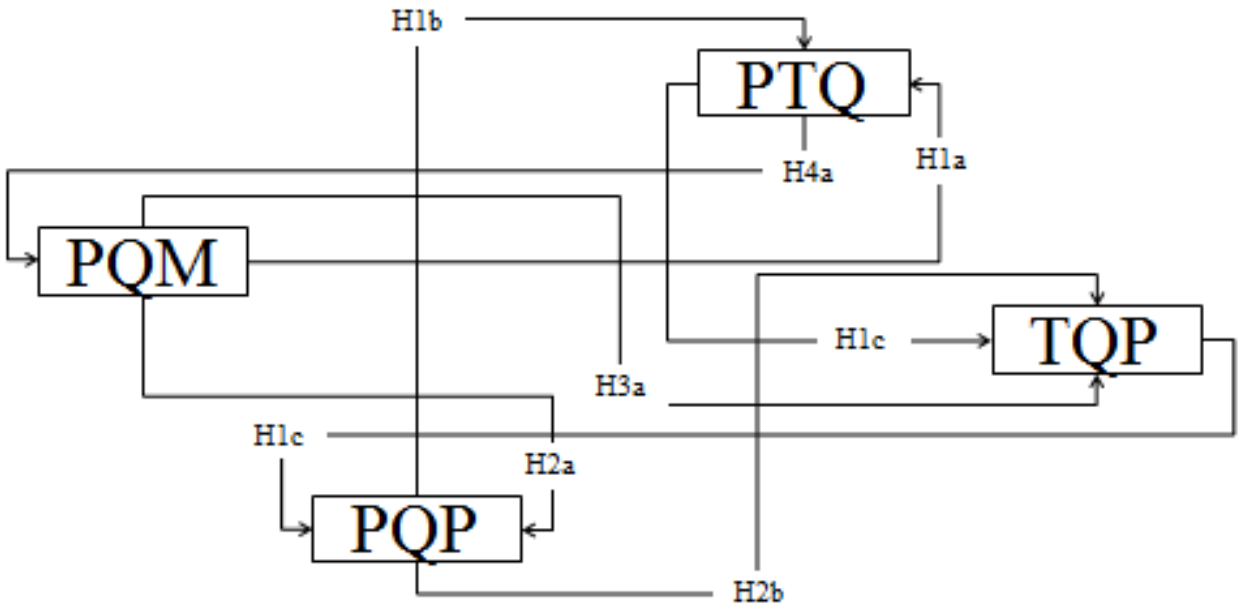

$\mathrm{TQP}=$ Total Quality Perceived, $\mathrm{PQM}=$ Perceived quality management, $\mathrm{PQP}=$ Perception of quality production, $\mathrm{PTQ}=$ Perceived Transfer of Quality

Fig.2: Specification model

Source: Prepared by the author 
In the following paragraphs, it is reported different events linked to wrong delivery made by the provider enterprise. Data have been changed or modified to protect confidential information of different enterprises and persons.

On Tuesday, July 5th, 2016 it was a wrong delivery of 8 panels of $260 \mathrm{~W}$ and a $2.0 \mathrm{KW}$ inverter, from the invoice X57X, whit tracking number AB00XX2970X, to our client, Renewable Energies Co. (SolarGroup). It because our last delivery to that client was to its address on the Southeast of Mexico.

In following figure, it is represented the invoice linked to mentioned delivery, that invoice was made by $12 \mathrm{PV}$ modules, 1 inverter of $2 \mathrm{KW}$ and $1 \mathrm{WiFi}$ stick for the inverter.

On Friday, July 15th, 2016, our sales manager communicates to us that the client complains because he was not received his product (delivery was sent to Southeast of Mexico). Sales department manager, request that logistics would sent 5 panels of $260 \mathrm{~W}$ and a WiFi stick, to other address in the northwest of Mexico.

They were delivered on Saturday, July 16th, 2016. The 5 panels and $1 \mathrm{WiFi}$ stick was sent to Delivery-service (center of Mexico's Office) by an outsourcing service by $\$ 500.00$ plus taxes $(\$ 580.00)$, which take the merchandize from the factory to the Delivery-service's office.

It was stared the process to recover the merchandise on July 18th, 2016, with almost daily callings to Southeast's office of Delivery-service and occasional calling to Deliveryservice's Call Center. Logistics department tried to establish a communication bridge. It is pointed out, that the communication with Southeast's office was very narrow and sometimes it is not possible communicate whit them.

There was also made some other calling to Southeast's Delivery-service Office. On Monday, July 18 it was made the phone call to Delivery-service's Call Center (XX XXX $\mathrm{X} 10$ 8352), logistics department was attended by Attendant I so they were obtained the following phone numbers:

(XXX) XX3 0953

(XXX) XX3 0972

(XXX) XX3 0973

On Tuesday, July 19, 2016, it was contacted Deliveryservice's Office in Southeast, so Attendant II ask to request the re-expedition of panels and inverter, by sending an email to attx@deliveryserv.com.mx and attiii@deliveryserv.com.mx, to Attendant X and Attendant III

On Friday, July 22nd, 2016, it was made a call again to Delivery-service (Southeast's Office), Attendant II answered, and gave the extension number of Attendant $\mathrm{X}$ and Attendant III. Attendant II take the phone call to the extension of Attendant III. When Attendant III, answered said that she has already sent the quotation to send back panels and inverter to factory. It was set a price of $\$ 5634$ pesos, so Logistics department request a quotation to Delivery-service Office (Center of Mexico's Office).

On Monday, July 25th, 2016, it was made another phone call to Southeast's Office, but there was no answer. On Tuesday 26th, 2016, it was called again to Southeast's Office, however in both lines the calling was stopped. It was made a phone call to Delivery-service's Call Center answering Attendant IV, she gave again the same phone numbers from Southeast's Office, and transferred the phone call to that office, that moment, answered Attendant II and logistics was hanged on the line, after a while, she asked to resend the request to Southeast's Office, so the request was resent.

On Thursday, July $28^{\text {th }}, 2016$, there was made another communication to Southeast's Office, and it was requested (Attendant $\mathrm{X}$ ), to resend the last request, due to he has not received mail nor document.

On Friday, July 29th, 2016 and Monday, August 1st, 2016, logistics try to communicate to Southeast's Office but there was no answer. On Monday, August 8th, 2016, logistics try to communicate to Southeast's Office but there still was no answer. On Tuesday, August 16th, 2016, logistics try to communicate to Southeast's Office but again, there was no answer. On Friday, August 19th, 2016, logistics try to communicate to Southeast's Office but there was no answer. On Monday, August 22nd, 2016, logistics try to communicate to Southeast's Office but there still was no answer. On Wednesday, August 31st, 2016, logistics department try again to communicate with Southeast's Office but still no answer.

On Friday, September 2nd, 2016, logistics department make a phone call to Delivery-service's Call Center, answering Attendant V, she request the basic information of the delivery an she found out the that merchandise was already picked up by the client, the person who picked up the merchandise was named: Mauricio E. A., merchandise has been taken by that person on August 11th, due to a connection failure the calling was ended. However, logistics department call back again, attending Attendant VI, she communicate logistics with Attendant III (in Southeast's Office), and Attendant III said she was checking and she said she was calling logistics back, but Attendant III did not make any phone call.

On Monday, September the 5th, 2016, logistics try to communicate to Southeast's Office but again, there was no 
answer. On Tuesday, September 61h, 2016, there was made a phone call to Southeast's Office, that time answered Attendant III: she made the link with Attendant VII, and Attendant VII request to ask via mail for support to recover the information of the case. An e-mail was sent to request the support to recover the evidences that Southeast's Office, have in order to integrate a report or (if necessary) to start a legal motion.

On Tuesday, September $8^{\text {th }}, 2016$, there was made a phone to Southeast's Office, but there was no answer. On Friday, September $9^{\text {th }}, 2016$, there was made a phone call to Southeast's Office and answered Attendant III. It was requested to talk with Attendant VII, en the phone call was transferred to the Attendant VII's extension. Attendant II answered and she said, it was not possible to talk to Attendant VII, but Attendant II was told about the situation, so she inform that it wouldn't be possible to recover any picture or video due to Southeast's Office data base only cover 21 days of record. However, Attendant II, agree to look for the document linked to tracking number ABO0XX2970X, and send it via mail to Logistics Department, to check the person who had signed and toke the merchandise.

Some days after that communication it was received the email in which a person of Renewable Energies Co.'s, required that merchandise would be given to Mauricio E. A. On a general way, to avoid problems on merchandize delivery, it was adopted a very strong attitude over the sales manager informal requests, respecting the stablished procedure to deliver merchandize and it was stablished a delivery's binnacle in warehouse and security gate.

It has been mentioned that sales manager asked for deliveries with quotation price documents or with request document, so production and logistics department, avoid the informal authorizations to delivery products or material. The process was stablished as a four steps method: (a) quotation price document (b) request document (c) invoice document and, (d) warehouse authorization.

After the problems, it was integrated a complete folder for each delivery and added some documents to complete it. It has been mentioned that, previously, a delivery can be authorized with a quotation or request document, but with the new way of working, it was required the following documents to authorize a delivery: i) quotation, which have the price authorized to sale the merchandize; ii) request, which includes authorized price and correct data and address linked to merchandize sold; iii) payment, it is the ticket or voucher (scanned, picture taken, or PDF) in which it can be seen the linked payment for each bought material (in the case of check, it was necessary to wait three days, until the amount of money was contrasted in the enterprise's bank account); iv) invoice, generated invoice after payment check in; v) sent data ticket, which have the information to be delivered by the outsourcing delivery service; vi) warehouse binnacle, where they were registered each material (invoiced) delivered (and contains data like: date, quantity, model, client, invoice, client's Federal Taxpayer Registry, driver, license plate, sent mode); vii) tracking number, it is the obtained document linked to delivery service

\section{METHOD}

Design.

A descriptive, exploratory and transversal study was carried out

\section{Sample.}

124 administrative and employees of a for-profit organization in the center of Mexico.34\% men and $66 \%$ women. $75 \%$ under 29 years old $(\mathrm{M}=24,13 \mathrm{SD}=0,18)$, $15 \%$ between 29 and 65 years old $(\mathrm{M}=41,23 \mathrm{SD}=10,17)$ and $5 \%$ over 65 years old $(\mathrm{M}=67,32 \mathrm{SD}=0,16) .22 \%$ with more than 7 working years $(\mathrm{M}=7,12 \mathrm{SD}=0,12), 38 \%$ with less than 7 and more than 3 working years $(\mathrm{M}=4,35 \mathrm{SD}=$ $0,84), 28 \%$ with less than 3 working years $(\mathrm{M}=2,43 \mathrm{SD}=$ $0,93)$.

\section{Instrument.}

The Total Perceived Quality Scale of Carreón (2016) was used, which includes four dimensions related to the management, production and the perceived transference of the quality of processes. each reagent includes five answer options that go from 00 it does not look like anything to my organization up to $4=$ it looks a lot like my organization.

\section{Proceeding.}

The Delphi technique was used for the processing of information and the elaboration of the reagents, comparing and integrating informative information to the total quality, as well as to the opinions of different administrative and employees in an organization for profit in the center of Mexico.

Subsequently, the surveys were applied in the human resources department as part of the staff recruitment and selection protocol, as well as part of the induction, training and training courses. The confidentiality and anonymity of the respondents was guaranteed in writing, as well as the warning that the results of the study did not affect their economic or work status.

The consistency of the instrument was estimated in terms of its questions from the answers, considering the Cronbach alpha parameter, as well as the Barttlet and KMO tests for 
adequacy and sphericity as preliminary tests to the validity, which was performed with a method of extraction of main axes with promax rotation. The comparison of the model with adjustment and residual parameters for the hypothesis test.

\section{RESULTS}

Table 1 shows the values of internal consistency of the instrument (alpha of 0.782 for the general scale and 0.780 to 0.795 for the subscales) which suggest that in other contexts and study samples the measurement of indicators and factors will be similar in up to $70 \%$ of cases.

Table.1: Descriptives of the instrument

\begin{tabular}{|c|c|c|c|c|c|c|c|c|}
\hline Code & Item & $\mathbf{M}$ & SD & $\mathbf{A}$ & F1 & F2 & F3 & $\mathbf{F 4}$ \\
\hline PQM1 & Prevention against risks & 3,21 & 0,19 & 0,701 & & & & 0,439 \\
\hline PQM2 & Disasterprevention & 3,25 & 0,28 & 0,702 & & & & 0,329 \\
\hline PQM3 & Preventionagainstviolence & 3,45 & 0,38 & 0,731 & & & & 0,431 \\
\hline PQM4 & Conflict prevention & 3,25 & 0,43 & 0,721 & & & & 0,403 \\
\hline PQM5 & Accident prevention & 3,46 & 0,54 & 0,742 & & & & 0,325 \\
\hline PQM6 & Prevention against epidemics & 3,67 & 0,83 & 0,721 & & & & 0,345 \\
\hline PQM7 & Preventionagainstdiseases & 3,93 & 0,48 & 0,742 & & & & 0,392 \\
\hline PQP1 & Production before demands & 3,02 & 0,91 & 0,743 & & & 0,431 & \\
\hline PQP2 & Competitiveness in the face of shortages & 3,01 & 0,29 & 0,741 & & & 0,423 & \\
\hline PQP3 & Entrepreneurship before needs & 3,26 & 0,39 & 0,752 & & & 0,504 & \\
\hline PQP4 & Continuous improvement in the face of backlog & 3,46 & 0,40 & 0,704 & & & 0,593 & \\
\hline PQP5 & Continuous improvement before absences & 3,41 & 0,53 & 0,725 & & & 0,502 & \\
\hline PQP6 & Continuous improvement against rotation & 3,24 & 0,45 & 0,721 & & & 0,501 & \\
\hline PQP7 & Continuous improvement against fraud & 3,25 & 0,41 & 0,793 & & & 0,504 & \\
\hline PTQ1 & Securities against corruption & 3,44 & 0,24 & 0,783 & & 0,305 & & \\
\hline PTQ2 & Empathy in the face of absenteeism & 3,12 & 0,32 & 0,702 & & 0,416 & & \\
\hline PTQ3 & Communication in disasters & 3.11 & 0,22 & 0,771 & & 0,406 & & \\
\hline PTQ4 & Conflict support & 3,02 & 0,33 & 0,772 & & 0,493 & & \\
\hline PTQ5 & Disappearance rules & 3,26 & 0,13 & 0,783 & & 0,492 & & \\
\hline PQT6 & Incentives for absenteeism & ,345 & 0,21 & 0,711 & & 0,501 & & \\
\hline PTQ7 & Emergency response & 3,46 & 0,34 & 0,705 & & 0,403 & & \\
\hline TQP1 & Attachment to the company & 3,47 & 0,02 & 0,783 & 0,403 & & & \\
\hline TQP2 & Thanks to the company & 3,41 & 0,38 & 0,783 & 0,302 & & & \\
\hline TQP3 & Recognition to the company & 3,26 & 0,49 & 0,756 & 0,392 & & & \\
\hline TQP4 & Delivery to the company & 3,27 & 0,93 & 0,736 & 0,491 & & & \\
\hline TQP5 & Put on the company shirt & 3,38 & 0,12 & 0,747 & 0,302 & & & \\
\hline TQP6 & Respect for company values & 3,04 & 0,21 & 0,746 & 0,321 & & & \\
\hline TQP7 & Execution of company protocols & 3,36 & 0,32 & 0,726 & 0,301 & & & \\
\hline
\end{tabular}

Method of extraction of the main axes, promax rotation. Adequacy and Sphericity $\int X^{2}=452,67(56 \mathrm{df}) \mathrm{p}=0,000: \mathrm{KMO}=$ $0,770 \mathrm{~J} . \mathrm{M}=$ Average, $\mathrm{DE}=$ Standard Deviation, $\mathrm{A}=$ Alpha, quitting the item value. F1 = Perceived Quality Management (alpha of the 0,780 and the $24 \%$ of the variance explained), F2 = Production Perceived Quality (alpha of the 0,785 and $21 \%$ of the variance explained), $3=$ Perceived Quality Transfer (alpha of the 0,790 and the $16 \%$ of the variance explained), F4 = Perception of Total Quality (alpha of the 0,795 and the $11 \%$ of the variance explained). All the items are answered with five response options: $0=$ it does not look like my organization, $1=$ it seems very little to my organization, $2=$ it seems little to my organization, 3 = it appears in something to my organization, $4=$ it looks a lot like my organization

Source: Elaborate with study data

Figure 3 shows that the perceived management of quality determines the perceived production of quality $(0,38)$, but this last factor is determinant of the total perceived quality $(0,35)$. 


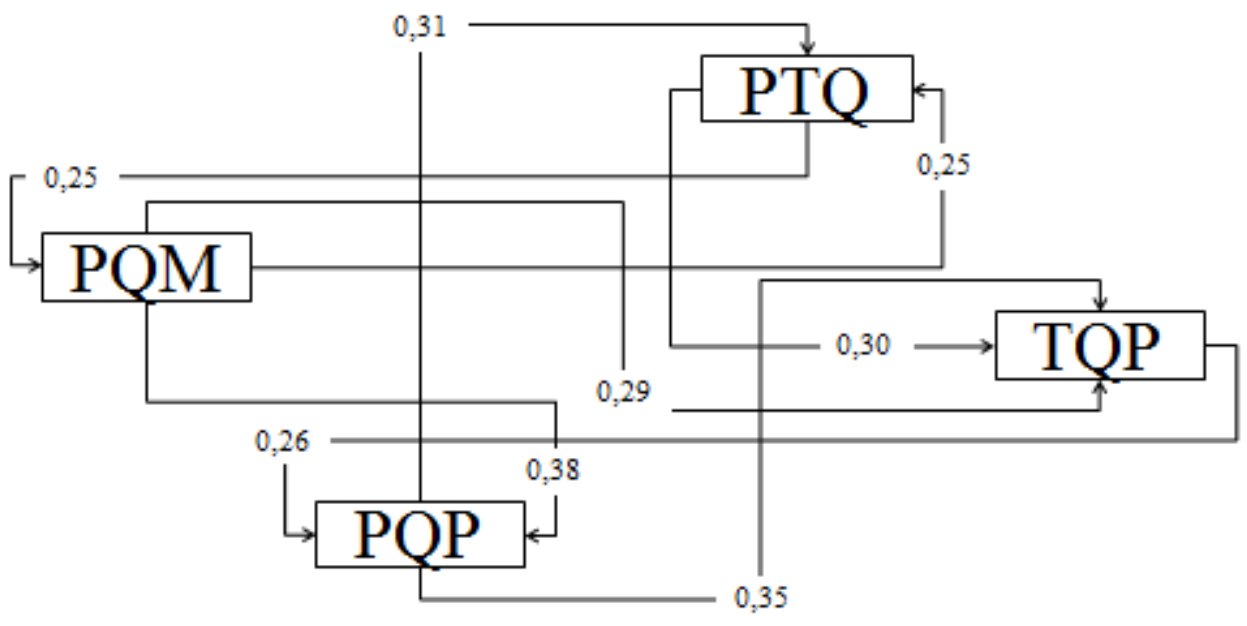

Fig.3: Structural model

Source: Elaborated with study data

The parameters of adjustment and residual $\int X^{2}=123,24$ (23df) $\mathrm{p}=0,010 ; \mathrm{GFI}=0,990 ; \mathrm{CFI}=, 991$; IFI $=0,993$; RMSEA $=0,007 \mathrm{~J}$ suggest the acceptance of the null hypothesis, relative to the relations of dependence between the factors used in the state of the question and demonstrated in the empirical test.

\section{Discussion}

The contribution of this study to the state of the question lies in the establishment of the reliability and validity of an instrument that measures the perception of management, production, transfer and the totality of the quality of the processes, but the type of non-experimental study, the type of non-probabilistic selection and the type of exploratory factor analysis limit the results of the study to the sample and the context of the investigation.

It is recommended to extend the study to other contexts and samples, using sophisticated analysis of factors such as the least squares technique in order to confirm the structure that underlies the perception of total quality, configured by three factors related to management, production and the transfer of knowledge.

It is so important for the organization to hold a substantial list of clients. It because, the client is the stakeholder that provides organization with the financial resource to going on with its labor and remain in its market share. However, it is more important to have a selected list of clients which can be recognized a loyal to the enterprise, and in which case can be a support for the organization.

With the strict control applied on the PV-modules enterprise, apparently mistakes where reduced. In the practice, there were some mistakes on deliveries, however, all of the was due to mistakes in the information provided by sale's agents, main mistakes detected still being in the address given by sale's agents and sale's manager.

With strict control strategy application, it was also possible to determine responsibilities. Due to wrong deliveries, responsibility for each mistake was charged to logistics department or production warehouse, however, when control strategy started it application, it was recognized that mistakes and/or omissions were mainly produced by data provided thorough sales department. Very little mistakes was due to Delivery-service omissions.

\section{CONCLUSION}

In the economy, the total quality is a preponderant factor in the processes and the products, although the labor climate that supposes such company is centered in the analysis of positions, worker cycle and the motivation of the worker as determining factors of a system of management, production and transfer of knowledge oriented to the continuous improvement of the scientific, technological and industrial process.

\section{REFERENCES}

[1] Acar, Z. and Acar, P. (2014). Their organizational culture types and effects on organizational performance in Turkish hospitals Emerging Markets Journal, 3 (3) : 1-15 [DOI: 10.5195 / emaj.2014.47].

[2] Andrejić, M., Kilibarda, M. \&Popović, V. (2015). Logistics failures in distribution process, $2^{\text {nd }}$ Logistics International Conference, available at: [http://logic.sf.bg.ac.rs/wpcontent/uploads/Papers/LOGIC2015/ID-41.pdf]. 
[3] Anicijevic, N. (2013). The mutual impact of organizational culture and structure. EconomicAnnals, 58 (198), 35-60

[4] Bohte, J. \& Meier, K. J. (2000). Goal displacement: Assessing the motivation for organizational cheating. Public Administration Review, 60 (2), 173-182, available

[http://onlinelibrary.wiley.com/doi/10.1111/00333352.00075/full].

[5] Carreón, J. Hernández, J., García, C. García, E., Rosas, F. Aguilar, J. (2014). Specifying a digital enterprise model for human development through intensive use of information and communication technologies. Rural Perspectives, 13 (25), 123-155

[6] Cavagnaro, E., \& George, H. (2017). The three levels of sustainability. Routledge. ISBN-13: 978-1-90609368-6, available at: [https://books.google.com.mx/books?hl=es\&lr=\&id=v qk0DwAAQBAJ\&oi=fnd\&pg=PT7\&dq=herman+daly $\% 27$ s+three+filter+economic+social+environment+19 87\&ots=ZWnL1VB-3E\&sig=LVcvxGU9RPT4ajTGITbJvALQ4c\&redir_esc=y\#v=onepa ge\&q\&f=false $]$.

[7] Cialdini, R.B, Petrova, P.K. \& Goldstein, N.J. (2004). The hidden costs of organizational dishonesty: companies that engage in unethical practices face consequences far more harmful than is traditionally recognized. The resulting damage can easily outweigh the short-term gains, MIT Sloan Management Review. 45 (3), 67-73, available at: [http://go.galegroup.com/ps/i.do?id=GALE\%7CA116 $484228 \&$ sid $=$ googleScholar $\& v=2.1 \& i t=r \& l i n k a c c e s s=$ fulltext\&issn=15329194\&p=AONE\&sw =w\&authCou $\mathrm{nt}=1 \& \mathrm{u}=$ uaeh1 \&selfRedirect=true $] \quad \&$ [http://mylearning.denverzoo.org/ets/companies/fbfdf7 ad-f5a3-416e-8c31-

62af837c7f0a/UserFiles/Article\%20Archive/Culture\% 20Articles/The\%20Hidden\%20Cost\%20of\%20Organi zational\%20Dishonesty_Article.pdf].

[8] Côté, R.P. y Cohen-Ronethal, E. (1998). Designing eco-industrial parks: a synthesis of some experiences, Journal of cleaner production, 6 (3-4), 181-188, DOI: [https://doi.org/10.1016/S0959-6526(98)00029-8], available at: [http://www.sciencedirect.com/science/article/pii/S095 9652698000298] \& [https://ac.elscdn.com/S0959652698000298/1-s2.0-

S0959652698000298-main.pdf?_tid=6b56d41c-9fb0$11 \mathrm{e} 7-\mathrm{a} 8 \mathrm{e} 0$ - 00000aacb35d\&acdnat=1506096752_8c6e6bdac145b7 fed82995e5a9dc42ff].

[9] Cruz, O., Arroyo, P. and Marmolejo, J. (2016). Technological innovations in logistics: inventory management, information systems and outsourcing operations. In M, Quintero, Sales, and J. Velázquez, E. (Coord.). Innovation and technology challenges for practical application in companies. (Pp. 165-178). Mexico: Miguel Angel Porrúa-UAEMEX.

[10] Escobar, R. (2014). Neural networks, cognitive processes and behavior analysis. International Journal of behaviorism, 2 (1), 23-43

[11] Hernandez, A. and Valencia, R. (2016). Innovation instruments: social networks in the internalization of micro, small and medium - sized Mexican companies. In M, Quintero., Sales, and J. Velázquez, E. (Coord.). Innovation and technology challenges for practical application in companies. (Pp. 4766). Mexico: Miguel Angel Porrúa-UAEMEX.

[12] Mendoza, E. Ramirez, L. and Atriano, R. (2016). Use of media and technology in creating an innovation system for the common good. In M, Quintero., Sales, and J. Velázquez, E. (Coord.). Innovation and technology challenges for practical application in companies. (Pp. 95-114). México: Miguel Ángel Porrúa-UAEMEX.

[13] Molina Ruiz, H.D. (2013). Aproximación de cálculo de la huella de carbono en una institución de educación media superior y superior. Innovación y Desarrollo Tecnológico Revista Digital, 5 (3), ISSN: 2007-4786.

[14] Molina Ruiz, H.D. (2015). Three levels analysis of sustainability's environmental dimension in México. Innovación y Desarrollo Tecnológico Revista Digital, 7 (4), ISSN: 2007-4786.

[15] National Institute of Statistics, Geography and Informatics. (2010) XI National Population Census. Mexico: INEGI

[16] Omotayo, and Adenike O., A. (2013). Impact of organizational culture on human resource practices: a study of selected Nigerian private universities. Journal of Competitiveness, 5 (4), 115-133 [DOI: 10.7441 / joc.2013.04.07]

[17] Quintero, M., Velázquez, E., Sales, and J. Padilla, S. (2016). A review of the state of the art on SMEs. What innovation studies? In M, Quintero, Sales, and J. Velázquez, E. (Coord.). Innovation and technology challenges for practical application in companies. (Pp. 31-43). Mexico: Miguel Ángel Porrúa-UAEMEX. 
[18]Robles, C., Alviter, L., Ortega, A. and Martinez, E. (2016). Culture of quality and innovation in microenterprises. In M, Quintero., Sales, and J. Velázquez, E. (Coord.).Innovation and technology challenges for practical application in companies. (Pp. 11-30). México: Miguel Ángel Porrúa-UAEMEX.

[19] Saansongu, E. and Ngutor, D. (2012). The influence of corporate culture of employee commitment to the organization. International Journal of Business and Management, 7 (22) : 1-8

[20]Sales, J., Quintero, M. Velázquez, E. (2016). Adaptation versus innovation: the formation of industrial districts from rural communities. Santa Cruz Atizapan and Chiconcuac.In M, Quintero., Sales, and J. Velázquez, E. (Coord.). Innovation and technology challenges for practical application in companies. (Pp. 181-199). México: Miguel Ángel Porrúa-UAEMEX.

[21] Vázquez, C., Barrientos, B., Quintero, M. Velázquez, E. (2016). Government support for innovation, technology and training for small and medium enterprises in México. In M, Quintero, Sales, and J. Velázquez, E. (Coord.). Innovation and technology challenges for practical application in companies. (Pp. 67-78). Mexico: Miguel Angel Porrúa-UAEMEX. 